\title{
Association of Vitamin E with Rapid Thawing on Goat Semen
}

\author{
Jurandy Mauro Penitente-Filho, ${ }^{1,2}$ Fabrício Albani Oliveira, ${ }^{1}$ \\ Carolina Rodriguez Jimenez, ${ }^{1}$ Erly Carrascal, ${ }^{1}$ Júlio César Oliveira Dias, ${ }^{1}$ \\ Gisele Dias Oliveira, ${ }^{3}$ Renata Gomes Silveira, ${ }^{4}$ Camila Oliveira Silveira, ${ }^{3}$ \\ and Ciro Alexandre Alves Torres ${ }^{1}$ \\ ${ }^{1}$ Department of Animal Science, Universidade Federal de Viçosa, 36570-900 Viçosa, MG, Brazil \\ ${ }^{2}$ Laboratory of Physiology and Animal Reproduction, Department of Animal Science, Universidade Federal de Viçosa, \\ P. H. Rolfs Avenue, 36570-900 Viçosa, MG, Brazil \\ ${ }^{3}$ Department of Veterinary, Federal University of Viçosa, P. H. Rolfs Avenue, 36570-900 Viçosa, MG, Brazil \\ ${ }^{4}$ Federal University of Espírito Santo, University Campus, 29500-000 Alegre, ES, Brazil
}

Correspondence should be addressed to Jurandy Mauro Penitente-Filho; penitentefilho@yahoo.com.br

Received 16 January 2014; Revised 14 March 2014; Accepted 22 March 2014; Published 11 May 2014

Academic Editor: Elisabetta Baldi

Copyright (C) 2014 Jurandy Mauro Penitente-Filho et al. This is an open access article distributed under the Creative Commons Attribution License, which permits unrestricted use, distribution, and reproduction in any medium, provided the original work is properly cited.

\begin{abstract}
The aim of this study was to evaluate the effects of vitamin E associated with rapid thawing on cryopreserved goat semen. Two bucks were used and eight ejaculates per animal were collected using artificial vagina. Semen was diluted with the following treatments: BIOXCELL (control), BIOXCELL + Equex (sodium lauryl sulphate) and BIOXCELL + vitamin E $100 \mu \mathrm{M}$. Semen was packaged into $0.25 \mathrm{~mL}$ straws and cooled at $5^{\circ} \mathrm{C}$ for 1 hour. Freezing was performed in liquid nitrogen vapor $\left(-155^{\circ} \mathrm{C}\right)$ during 15 minutes. Then, the straws were immersed in liquid nitrogen $\left(-196^{\circ} \mathrm{C}\right)$. Straws were thawed at $38^{\circ} \mathrm{C} / 60$ seconds or at $60^{\circ} \mathrm{C} / 7$ seconds with immediate sperm analysis. Hypoosmotic swelling test was performed adding a $20 \mu \mathrm{L}$ aliquot of thawed semen to $1 \mathrm{~mL}$ of hypoosmotic solution $\left(100 \mathrm{mOsm} \cdot \mathrm{Kg}^{-1}\right)$ followed by incubation during 60 minutes in water bath $\left(38^{\circ} \mathrm{C}\right)$. Vitamin $\mathrm{E}$ did not affect any studied parameters $(P>0.05)$. Nevertheless, defrosting rate of $60^{\circ} \mathrm{C} / 7$ seconds improved sperm membrane functional integrity $(P<0.05)$. Current knowledge about goat semen cryopreservation is not sufficient to ensure high post-thawing recovery rates; thus, this study brings important data about using antioxidants and different thawing rates on cryopreservation process.
\end{abstract}

\section{Introduction}

Oxidative stress affects the organism when the generation of reactive oxygen species (ROS) exceeds the capacity of the cells to protect or repair themselves [1]. Reactive oxygen species can initiate lipid peroxidation and DNA damage leading to mutagenesis, carcinogenesis, and cell death, if the antioxidant system is impaired [2]. In physiological conditions, spermatozoa exhibit a capacity to generate ROS, but there is equilibrium between the generation of ROS and antioxidant strategies, leaving only a critical amount of ROS required for normal sperm functions, as capacitation, acrosome reaction, and fusion with the oocyte membrane [3]. Excessive production of ROS, however, results in peroxidation of the unsaturated fatty acids in sperm membrane, therefore resulting in defective sperm function [2].
In this context, the antioxidants appear as potentials constituent for cryoprotectors in the goat semen freezing process. Vitamin E is a primary component of sperm antioxidant system [4], and one of the main membrane protectors against ROS [5]. Cryopreservation of goat semen using Equex (sodium lauryl sulphate) showed beneficial effect on the parameters of the thawed goat semen at concentrations of 0.5 to $1 \%$ [6]. Therefore, Equex at a concentration of $0.008 \% \mathrm{v} / \mathrm{v}$ was used as an emulsifier of vitamin $\mathrm{E}[7,8]$ in the freezingthawing process.

The main damage caused by reheating occurs when the sperm passes through the critical zone between $-50^{\circ} \mathrm{C}$ and $-15^{\circ} \mathrm{C}$ or $-5^{\circ} \mathrm{C}$ [9]. Moreover, sperm undergoes osmotic stress when duration of defrosting is insufficient to efflux the excess of cryoprotectants from within the cells. Sperm becomes 
TABLE 1: Baseline values and characteristics of the ejaculates that were used in this study (mean \pm standard error of mean).

\begin{tabular}{lcc}
\hline Parameter & Baseline & Fresh semen \\
\hline Progressive motility (\%) & $>70$ & $84.1 \pm 1.3$ \\
Sperm vigor (0-5) & $>3$ & $3.6 \pm 0.1$ \\
Mass movement (0-5) & $>3$ & $3.2 \pm 0.1$ \\
Total abnormal sperm (\%) & $<20$ & $15.3 \pm 1.8$ \\
\hline
\end{tabular}

turgid and smooth due to the abrupt dilution of the medium caused by defrosting of extracellular ice [10].

Thawing procedure should be performed at high temperature to minimize recrystallization. Thus, this study aimed to evaluate whether vitamin $\mathrm{E}$ associated with rapid thawing can reduce the damage on goat semen which is caused by freezing-thawing process.

\section{Material and Methods}

2.1. Animals: Collection and Physical Analyses of the Semen. Two bucks, Parda Alpina breed, from Universidade Federal de Viçosa, MG, with good body condition and three years old, were used. Animals were evaluated and approved for reproduction through andrological examination in agreement with quality patterns of fresh semen extolled by the Brazilian College of Animal Reproduction [11].

The collection period extended from April to May, 2010. Ejaculates were obtained through artificial vagina in the presence of an estrous doe restrained in collection trunk. Ejaculates were collected every 2 days, totalizing 8 ejaculates per animal.

After collections, semen physical analyses were performed: sperm motility (0-100\%), vigor and mass movement (score from 0 to 5). Sperm morphology and concentration (sptz/mL) were done by separated samples. All the ejaculates that were used in this experiment followed the parameters summarized in Table 1 [11].

2.2. Stock Solutions of Vitamin E. An aliquot of Equex (sodium lauryl sulphate; $0.8 \mathrm{~mL}$ ) was diluted in distilled water to prepare $100 \mathrm{~mL}$ of Equex solution $(0.8 \% \mathrm{v} / \mathrm{v})$, and $50 \mathrm{~mL}$ of this solution was distributed in $0.5 \mathrm{~mL}$ tubes and frozen at $-20^{\circ} \mathrm{C}$ until use. Vitamin E (DL- $\alpha$-Tocopherol acetate, SigmaAldrich) solution $(10 \mathrm{mM})$ was prepared with the remaining $50 \mathrm{~mL}$. This solution was homogenized with a magnetic stirrer, stored in $0.5 \mathrm{~mL}$ tubes, and frozen at $-20^{\circ} \mathrm{C}$. Vitamin $\mathrm{E}$ weight was done in a room with dim light due to its photosensitivity [7].

2.3. Semen Freezing and Experimental Design. After physical examination, $10 \mu \mathrm{L}$ of fresh semen was diluted $(1: 200)$ in Hancock solution [11] for sperm concentration analysis (haemocytometer method), for calculation of the final volume of diluent to be added.

For dilution, each ejaculate was divided into three treatments: BIOXCELL (control; Table 2), BIOXCELL + Equex, and BIOXCELL + vitamin E $100 \mu \mathrm{M}$. Vitamin E and Equex
TABLE 2: Chemical composition of the diluent (Bioxcell-IMV).

\begin{tabular}{lc}
\hline Components & $\mathrm{g} / \mathrm{L}$ \\
\hline Tris & 2.3 \\
Sodium citrate & 6.2 \\
Potassium chloride & 0.8 \\
Fructose & 1.2 \\
Monohydrate lactose & 0.8 \\
Glycine & 0.2 \\
Anhydrous glucose & 0.5 \\
Taurine & 0.005 \\
Gentamicin sulfate & 0.24 \\
Tylosin tartrate & 0.33 \\
Linco-Spectin 100 & 0.383 \\
Glycerol & 40.2 \\
Hydrate of calcium lactate & 0.7 \\
Soy lecithin & 1.5 \\
Monohydrate citric acid & 2.5 \\
Ultrapure water & $1000 \mathrm{~mL}$ \\
\hline
\end{tabular}

were added to final dilutions and fixed in $10 \mu \mathrm{L}$ of stock solution per $\mathrm{mL}(1: 100)$.

After dilution, semen was packaged into $0.25 \mathrm{~mL}$ straws with $50 \times 10^{6}$ sperm. Straws were placed in a $20 \mathrm{~mL}$ test tube coated with refill (plastic bag) and placed into a $240 \mathrm{~mL}$ plastic container containing $125 \mathrm{~mL}$ of ethyl alcohol. Container was placed horizontally inside a refrigerator, with internal temperature at $5^{\circ} \mathrm{C}$, with cooling rate of $-0.38^{\circ} \mathrm{C} \cdot \mathrm{min}^{-1}$ for 45 minutes and 15 minutes of equilibration period [12].

Prefreezing was performed during 15 minutes in liquid nitrogen vapor with prefreezing rate of $-10.7^{\circ} \mathrm{C} \cdot \mathrm{min}^{-1}$; for this, straws were placed $5 \mathrm{~cm}$ above liquid nitrogen [13]. After this period, straws were submerged in liquid nitrogen $\left(-196^{\circ} \mathrm{C}\right)$ and stored in cryogenic cylinder.

Ten days after freezing, for each treatment, there were two types of thawing, both in water bath, as follows: at $38^{\circ} \mathrm{C}$ for 60 seconds or at $60^{\circ} \mathrm{C}$ for 7 seconds followed by 60 seconds at $38^{\circ} \mathrm{C}$ (Table 3 ). The semen was placed in tubes and homogenized for immediate analysis of sperm motility and vigor by phase contrast microscopy at 100x increase.

2.4. Hypoosmotic Swelling Test (HOST). The functional integrity of the sperm membrane was evaluated by the hypoosmotic swelling test (HOST), using a hypoosmotic solution of $100 \mathrm{mOsmol} \cdot \mathrm{Kg}^{-1}$. For the preparation of hypoosmotic solution, $9 \mathrm{~g}$ of fructose and $4.9 \mathrm{~g}$ of trisodium citrate were dissolved in $1000 \mathrm{~mL}$ of deionized water [14].

An aliquot of $20 \mu \mathrm{L}$ of thawed semen was added to $1 \mathrm{~mL}$ of hypoosmotic solution and incubated for 60 minutes in water bath at $38^{\circ} \mathrm{C}$. Later, $0.5 \mathrm{~mL}$ of Hancock solution was added to the samples to fix them. Each HOST sample was mounted between glass slide and coverslip and examined in phase contrast microscope at 1000x increase. One hundred cells were analyzed per sample; the spermatozoa were classified by 
TABLE 3: Experimental design.

\begin{tabular}{lcc}
\hline $\begin{array}{l}\text { Semen } \\
\text { samples }\end{array}$ & Treatment & Thawing \\
\hline & Control & $38^{\circ} \mathrm{C} / 60$ seconds \\
& Control & $60^{\circ} \mathrm{C} / 7$ seconds followed by \\
& $38^{\circ} \mathrm{C} / 60$ seconds \\
& Equex & $38^{\circ} \mathrm{C} / 60$ seconds \\
& Equex & $60^{\circ} \mathrm{C} / 7$ seconds followed by \\
& Vitamin E & $38^{\circ} \mathrm{C} / 60$ seconds \\
& $100 \mu \mathrm{M}$ & $38^{\circ} \mathrm{C} / 60$ seconds \\
& Vitamin E & $60^{\circ} \mathrm{C} / 7$ seconds followed by \\
& $100 \mu \mathrm{M}$ & $38^{\circ} \mathrm{C} / 60$ seconds \\
\hline
\end{tabular}

the presence or absence of coiled tail. Result was determined as percentage, and the calculation was done as follows: HOST $\%=(\%$ change in the tail after HOST $)-(\%$ change in the tail before HOST).

2.5. Statistical Analysis. Experiment was carried out in a completely randomized design in factorial assay $3 \times 2(03$ diluents $\times 02$ thawing temperatures). For statistical analysis, the Statistical Analysis System [15] was used. Data of sperm motility and HOST were submitted to analysis of variance associated to Tukey's test using the PROC ANOVA, and interaction between diluents and thawing temperatures was assessed by the PROC GLM. Data of sperm vigor were analyzed by Wilcoxon test. Analysis of correlation between HOST and sperm motility and vigor was performed by Pearson's correlation and Spearman's correlation, respectively. A regression analysis of HOST and sperm motility was assessed by PROC REG. Significant level adopted was 5\% of probability.

\section{Results}

Sperm motility, sperm vigor, and hypoosmotic swelling test showed no differences among studied diluents $(P>0.05$; Table 4). Furthermore, there was no interaction between thawing temperature and diluents $(P>0.05)$.

Sperm motility and vigor showed no difference $(P>0.05)$ between the thawing rates (Table 5). Nevertheless, defrosting at $60^{\circ} \mathrm{C} / 7$ seconds increased functional integrity of sperm membrane $(P<0.05$; Table 5).

\section{Discussion}

The effect of vitamin E on semen characteristics of domestic mammals has been extensively studied. Addition of vitamin E to animal diets showed goods results in sheep [16] and goats [17]. Nevertheless, inclusion of vitamin E to the semen extenders showed variable results among species. Vitamin E at a concentration of $100 \mu \mathrm{M}$ improved bull sperm membrane integrity, but it did not improve sperm motility and vigor [7]. Moreover, addition of vitamin E $(100 \mu \mathrm{M})$ to semen
TABLE 4: Sperm motility, sperm vigor, and hypoosmotic swelling test (HOST) of thawed goat semen cryopreserved with different media (mean \pm standard error of mean).

\begin{tabular}{lccc}
\hline Seminal parameters & Control & Equex & VE $100 \mu \mathrm{M}$ \\
\hline Sperm motility (\%) & $30.2 \pm 2.7$ & $28.4 \pm 2.8$ & $28.3 \pm 2.7$ \\
HOST (\%) & $25.5 \pm 4.0$ & $27.4 \pm 3.9$ & $26.4 \pm 3.0$ \\
Sperm Vigor & $2.0 \pm 0.1$ & $1.9 \pm 0.1$ & $2.0 \pm 0.1$ \\
\hline
\end{tabular}

$P>0.05$; VE: vitamin E; HOST: hypoosmotic swelling test.

TABLE 5: Sperm motility, sperm vigor, and hypoosmotic swelling test (HOST) of thawed goat semen thawed at different temperatures (mean \pm standard error of mean).

\begin{tabular}{lcc}
\hline Seminal parameters & $38^{\circ} \mathrm{C} / 60 \mathrm{~s}$ & $60^{\circ} \mathrm{C} / 7 \mathrm{~s}$ \\
\hline Sperm motility (\%) & $27.2 \pm 1.5^{\mathrm{a}}$ & $30.7 \pm 1.6^{\mathrm{a}}$ \\
HOST (\%) & $23.8 \pm 1.9^{\mathrm{b}}$ & $29.3 \pm 2.0^{\mathrm{a}}$ \\
Sperm vigor & $1.9 \pm 0.1^{\mathrm{a}}$ & $2.1 \pm 0.1^{\mathrm{a}}$ \\
\hline
\end{tabular}

${ }^{\mathrm{a}, \mathrm{b}}$ Different letters in the row are statistically different $(P<0.05)$; HOST: hypoosmotic swelling test.

extender did not improve its quality in ram [18] and goats [8] supporting the present study.

The beneficial effect of Equex at concentrations of 0.5 to $1 \%$ on the parameters of the goat thawed semen has been reported [6]; nevertheless, these concentrations are larger than the $0.008 \%$ used in this study in which Equex was used as a Vitamin E emulsifier; however, even used as an emulsifier, Equex could improve bull sperm membrane integrity in the freezing process [7].

Thawing rate affects substantially quality of cryopreserved semen [19]. The ideal rate which recovers a great number of spermatozoa is variable among species. Thawing procedure should be performed at a high temperature to avoid recrystallization. The main damage caused by reheating occurs when the sperm passes through a critical zone between $-50^{\circ} \mathrm{C}$ and $-15^{\circ} \mathrm{C}$ or $-5^{\circ} \mathrm{C}$ [9]. Sperm becomes turgid and smooth due to the abrupt dilution of the medium caused by defrosting of extracellular ice [10].

In this study, thawing rate of $60^{\circ} \mathrm{C} / 7$ seconds $\mathrm{did}$ not improve sperm motility when compared to thawing rate of $38^{\circ} \mathrm{C} / 60$ seconds $(P>0.05)$, probably because these two thawing rates do not possess sufficient differences in the formation of large ice crystals during crystallization to be able to affect goat sperm motility.

In bovine, there is a plateau in the relationship between thawing rate and sperm survival, so that increase in thawing temperature between $50^{\circ} \mathrm{C}$ and $70^{\circ} \mathrm{C}$ does not improve sperm motility [20]. It was hypothesized that, for goat semen, there is a lower plateau and temperatures between $37^{\circ} \mathrm{C}$ and $55^{\circ} \mathrm{C}$ also do not promote differences in the quality of thawed semen [21].

It is possible that temperatures higher than that used in this study could improve cryopreserved goat semen parameters. Tuli et al. [19] observed an increase on progressive motility and plasma membrane integrity of goat semen thawed at $70^{\circ} \mathrm{C} / 7$ seconds in comparison with the thawing rate of $37^{\circ} \mathrm{C} / 2$ minutes and $40^{\circ} \mathrm{C} / 20$ seconds. However, attention should 


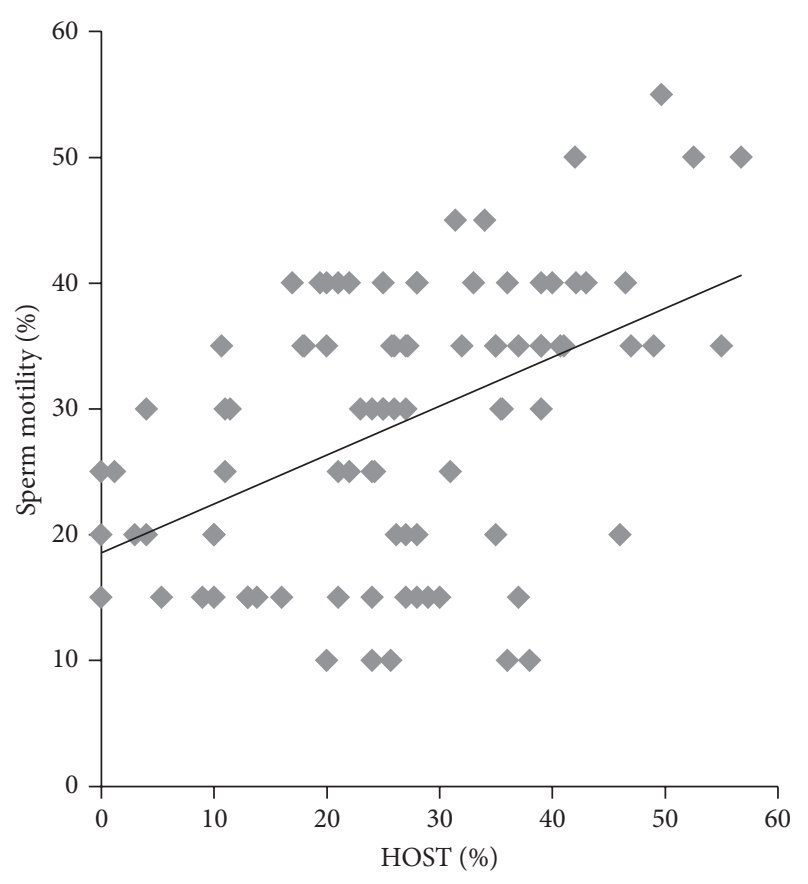

FIGURE 1: Dispersion graphic between sperm motility and HOST $\left(R^{2}=0.22\right)$.

be given to temperature and time of thawing; temperatures higher than $37^{\circ} \mathrm{C}$ leave the time as a critical variable. High temperatures can increase sperm mortality rates if applied improperly [22].

Nevertheless, the functional integrity of sperm membrane assessed by HOST was higher when semen was defrosted at $60^{\circ} \mathrm{C} / 7$ seconds $(P<0.05)$. This thawing rate probably is able to reduce formation of large ice crystals enough to protect the functional integrity of the goat sperm membrane. Correlation analysis showed no correlation between HOST and sperm vigor $(P>0.05)$, but there was correlation between HOST and sperm motility $(r=0.47$; $P<0.001)$; besides, a regression analysis resulted in a linear function expressed by Sperm motility $=0.18547+0.38924$ HOST $\left(P<0.001 ; R^{2}=0.22\right.$; Figure 1$)$.

Although the HOST cannot be used as the unique parameter to assess sperm quality [23], it is a good supplemental test to improve the efficiency of the sperm analysis [24] which is supported by the $R^{2}$ value that was found in this study.

\section{Conclusions}

In conclusion, vitamin $\mathrm{E}$ did not affect the studied parameters of the thawed goat semen. Defrosting goat semen at $60^{\circ} \mathrm{C} / 7$ seconds followed by of $38^{\circ} \mathrm{C} / 60$ seconds can increase functional integrity of the goat sperm membrane but not the sperm motility and vigor. More studies are still required to understand the effective role of the antioxidants in goat semen as well as the effect of different thawing rates that may be used in the goat sperm freezing-thawing process.

\section{Conflict of Interests}

The authors declare that there is no conflict of interests regarding the publication of this paper.

\section{Acknowledgments}

The authors thank FAPEMIG and CNPq for the financial support.

\section{References}

[1] P. Venditti and S. Di Meo, "Thyroid hormone-induced oxidative stress," Cellular and Molecular Life Sciences, vol. 63, no. 4, pp. 414-434, 2006.

[2] M. I. Yousef, G. A. Abdallah, and K. I. Kamel, "Effect of ascorbic acid and Vitamin E supplementation on semen quality and biochemical parameters of male rabbits," Animal Reproduction Science, vol. 76, no. 1-2, pp. 99-111, 2003.

[3] D. Yue, L. Yan, H. Luo, X. Xu, and X. Jin, "Effect of Vitamin E supplementation on semen quality and the testicular cell membranal and mitochondrial antioxidant abilities in Aohan fine-wool sheep," Animal Reproduction Science, vol. 118, no. 24, pp. 217-222, 2010.

[4] P. Surai, I. Kostjuk, G. Wishart et al., "Effect of vitamin E and selenium supplementation of cockerel diets on glutathione peroxidase activity and lipid peroxidation susceptibility in sperm, testes, and liver," Biological Trace Element Research, vol. 64, no. 1-3, pp. 119-132, 1998.

[5] M. Akiyama, "In vivo scavenging effect of ethylcysteine on reactive oxygen species in human semen," Nippon Hinyokika Gakkai Zasshi, vol. 90, no. 3, pp. 421-428, 1999.

[6] R. F. Bittencourt, A. D. L. Ribeiro Filho, M. C. C. Lima et al., "Effects of a calcium chelator, a detergent and the soybean lecithin on the quality of the frozen-thawed goat semen," Brazilian Journal of Veterinary Research and Animal Science, vol. 45, no. 4, pp. 305-312, 2008.

[7] J. C. Borges, Use of antioxidants associated or not with emulsifier in bovine semen cryopreservation [M.S. thesis], Federal University of Viçosa, Viçosa, Brazil, 2003.

[8] J. M. Penitente-Filho, C. A. A. Torres, M. C. R. Santos et al., "Vitamin E on cryopreservation of goat semen," in Proceedings of the 19th Brazilian Congress of Animal Reproduction, 2011.

[9] F. Lahnsteiner, "Semen cryopreservation in the Salmonidae and in the Northern pike," Aquaculture Research, vol. 31, no. 3, pp. 245-258, 2000.

[10] S. M. H. Andrabi, "Fundamental principles of cryopreservation of Bos taurus and Bos indicus bull spermatozoa," International Journal of Agriculture and Biology, vol. 9, pp. 367-369, 2007.

[11] CBRA, Manual For Andrological Examination and Evaluation of Animal Semen, (Portuguese), Brazilian College of Animal Reproduction, Belo Horizonte Minas Gerais, Brazil, 1998.

[12] R. Fürst, G. R. Carvalho, C. O. M. Fürst, V. Mafilli, J. R. M. Ruas, and A. M. Borges, "Effect of the equine semen cooling on the freezibility," Arquivo Brasileiro De Medicina Veterinária E Zootecnia, vol. 57, pp. 599-607, 2005 (Portuguese).

[13] V. H. Chirineá, M. I. M. Martins, F. F. Souza, J. M. Tebet, F. O. Papa, and M. D. Lopes, "Morphofunctional characteristics of the cooled and frozen canine semen, using two different diluents," Ciência Animal Brasileira, vol. 7, pp. 407-415, 2006 (Portuguese). 
[14] J. F. Fonseca, C. A. A. Torres, A. D. F. Santos, and H. Rovay, "Hypoosmotic swelling test in goat spermatozoa," Revista Brasileira De Reprodução Animal, vol. 25, pp. 436-438, 2001.

[15] SAS Institute Inc, SAS/STAT 9. 0 User's Guide, SAS Institute Inc, Cary, NC, USA, 2002.

[16] A. Dokukin and A. Alyakaev, "Vitamin E in rations for rams," Ovtsevodstvo, vol. 2, pp. 37-39, 1986.

[17] Z. Hong, L. Hailing, M. Hui, and Z. Guijie, "Effect of vitamin E supplementation on development of reproductive organs in Boer goat," Animal Reproduction Science, vol. 113, no. 1-4, pp. 93-101, 2009.

[18] G. C. Upreti, K. Jensen, J. E. Oliver, D. M. Duganzich, R. Munday, and J. F. Smith, "Motility of ram spermatozoa during storage in a chemically-defined diluent containing antioxidants," Animal Reproduction Science, vol. 48, no. 2-4, pp. 269278, 1997.

[19] R. K. Tuli, R. Schmidt-Baulain, and W. Holtz, "Influence of thawing temperature on viability and release of glutamic oxaloacetic transaminase in frozen semen from Boer goats," Animal Reproduction Science, vol. 25, no. 2, pp. 125-131, 1991.

[20] H. Woelders and A. P. Malva, "How important is the cooling rate in cryopreservation of (bull) semen, and what is its relation to thawing rate and glycerol concentration," Reproduction in Domestic Animals, vol. 33, no. 3-4, pp. 299-305, 1998.

[21] F. S. B. Bezerra, Cryopreservation of goat semen: effect of different straws, thawing rates and cryoprotectors [M.S. thesis], Federal University of Semi-Árido, Mossoró, Brazil, 2009.

[22] P. H. Purdy, "A review on goat sperm cryopreservation," Small Ruminant Research, vol. 63, no. 3, pp. 215-225, 2006.

[23] C. A. S. Bispo, G. Pugliesi, P. Galvão et al., "Effect of low and high egg yolk concentrations in the semen extender for goat semen cryopreservation," Small Ruminant Research, vol. 100, no. 1, pp. 54-58, 2011.

[24] E. F. de Castilho, J. D. Guimarães, L. F. Martins, R. O. Pinho, S. E. F. Guimarães, and C. J. B. Espeschit, "Use of propolis and ascorbic acid on goat semen cryopreservation," Revista Brasileira de Zootecnia, vol. 38, no. 12, pp. 2335-2345, 2009 (Portuguese). 

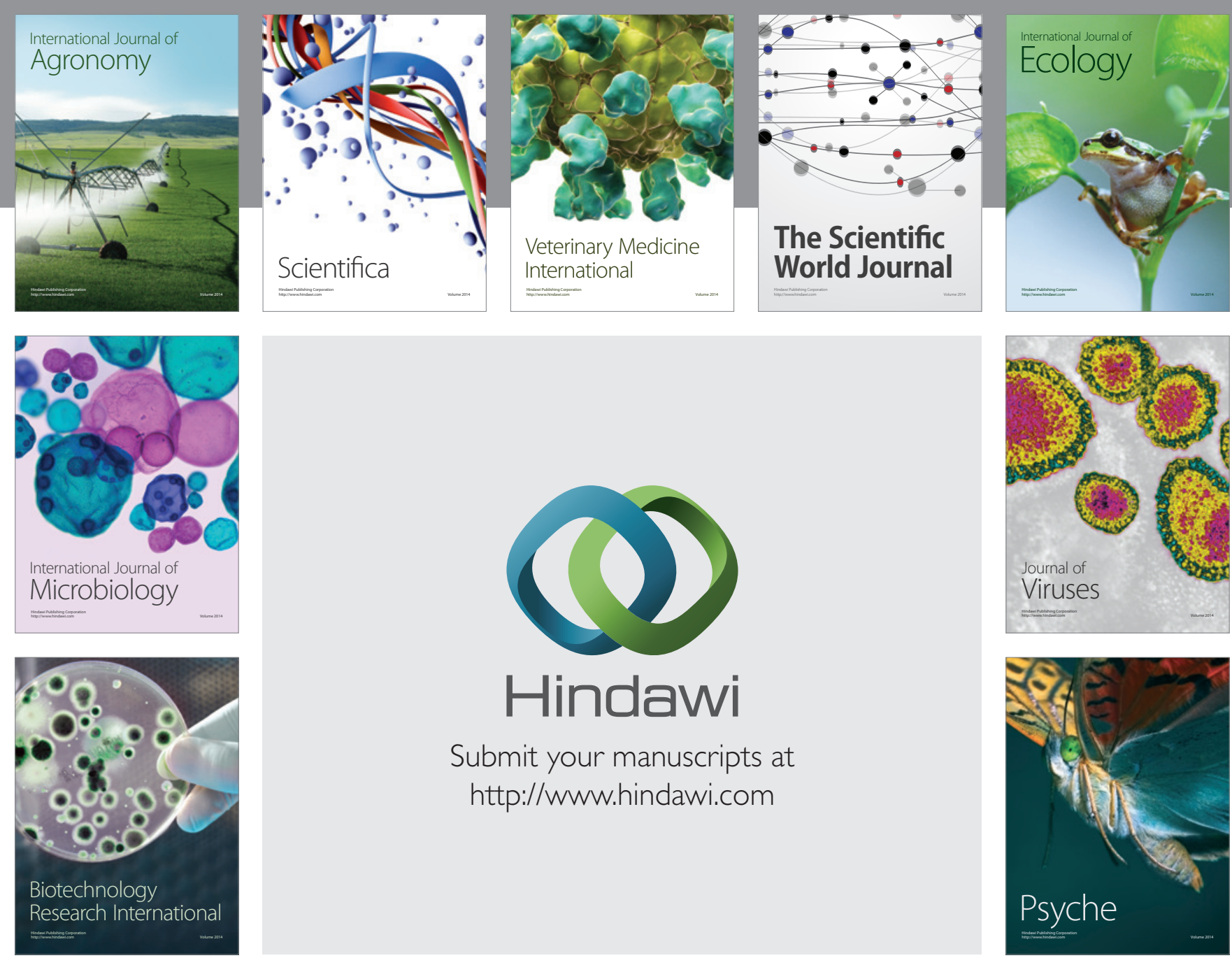

Submit your manuscripts at http://www.hindawi.com
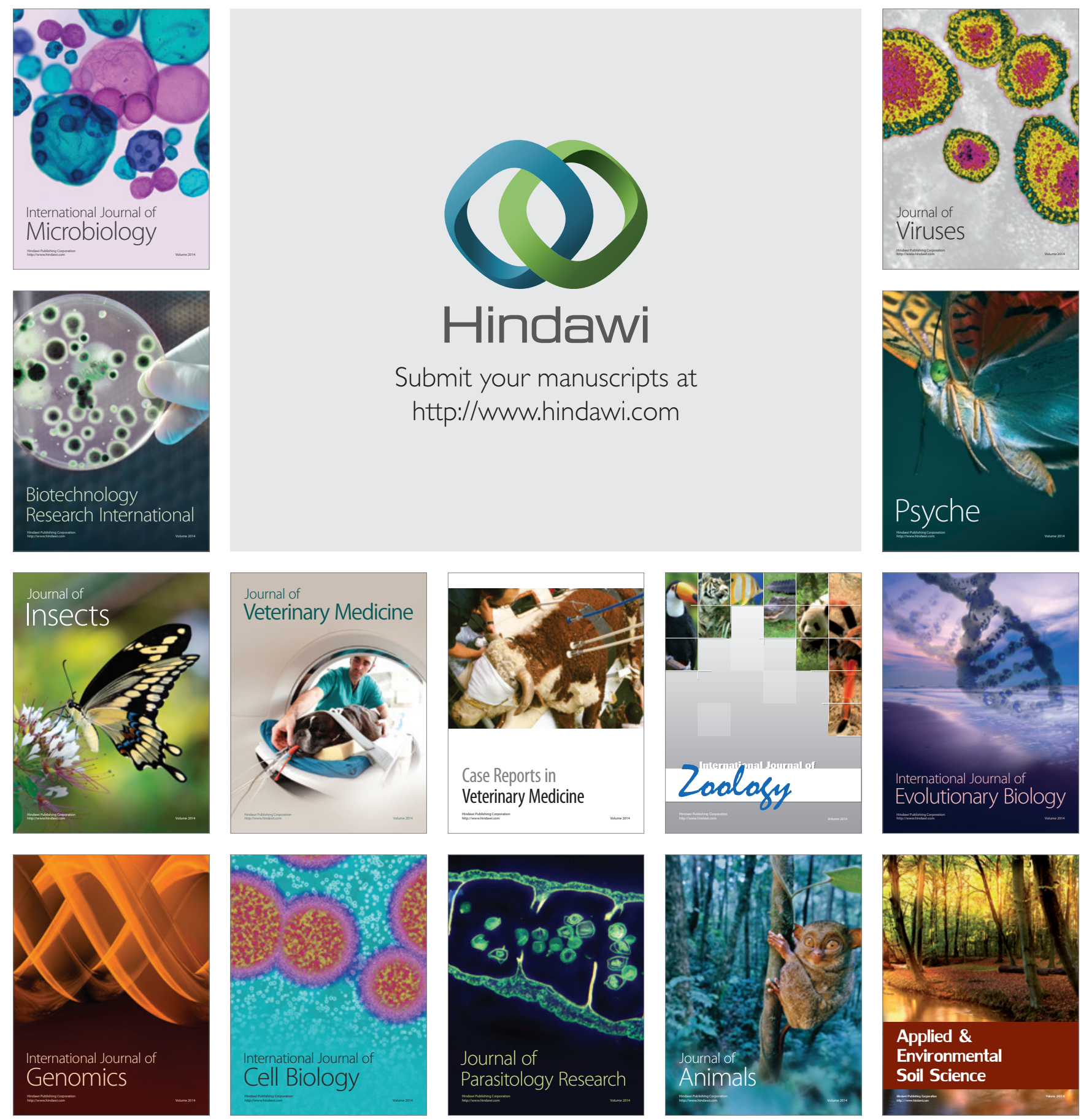